\title{
Development of E-Health System with Resource Allocation Forecasting for Local Health Communities
}

\author{
John Paul P. Miranda \\ Don Honorio Ventura State University, Philippines, johnpaul.p.miranda@gmail.com
}

\begin{abstract}
Healthcare providers continue to make progress toward more effective, informed and personalized care through the application of Information Technology. The enhancements in the current processes of health units in one city in the Philippines were based on the interviews, observations, and content analysis. 12 informants have participated in the study in which all of them have background in medicine and have firsthand experience on the existing transactions among health units. The informants were interviewed in 10 different occasions. In order to efficiently help the health units in projecting the needed medicines and supplies, Simple Moving Average (SMA) was implemented in the system, it forecasts using the historical data on distributed medicines and supplies to the residents. A resource allocation functionality was also added to the system based on the forecasted results. Relevant capabilities of the system such as enhancing oversight function through traceability of medicines and supplies the illness associated while promoting accountability was also added. Using an alpha testing by 5 ICT experts, the system was found to be acceptable for the quality standard set by ISO 25010, Conclusions and recommendations are also offered.
\end{abstract}

Key words: Community health units, e-health system, e-management, forecasting, simple moving average.

\section{INTRODUCTION}

Implementation of information management system varies, allowing organizations to rapidly deploy the system using different available technologies, from stand-alone using desktop PC or handheld, to modern web through online systems and mobile applications for real-time record-keeping. The Internet permits a system or application available 24/7, and data and up-to-date information can be at hand. This would help organizations having people in multiple locations to take control of their tasks and secure the data and information that they need. Different organizations maintain different sets of data and information based on the nature of business operations and its assets.
As a general rule, most organizations usually devise a strategic plan based on the available data, this is true for most organization in various sectors. However, many companies face a lot of challenges and risks due to the lack of clear policies, systematic record management and right procedures. Moreover, failing to protect vital information as well as to comply with the standards of record-keeping will ultimately lead to waste of available resources [17]. While, Ratchinsky [13] said that organizations should look forward in centralize and extend their applications to ensure high performance and exercise control over it. Moreover, organizations should respond on the trend on data consolidation whether in-house or through third party and with the help of technology. This only proves that healthcare providers should continue to seek more effective and efficient way to improve their services in which IT plays a vital role [27]. Wang et al [21] said that web-based application provides healthcare providers a way to ensure continuous access to information anytime and any location. Takhti et al [10] said that the quality, reliability and timeliness of health information system can influence the work of those in healthcare. They further stated that such system can be used to optimize human resources and improve services. Another study by Kartawiguna et al [27] concluded that IT capabilities among health institutions plays a vital role in improving clinical performance.

Although a law in the Philippines [35] ensures all public records held by government offices including the health units under each LGUs must have a permanent repository for effective governance together with the $\mathrm{DOH}$ visions to use new technology to enable electronic transmissions of health-care related information among health-related institutions through a join resolution [36], many healthcare provides specifically public health units in the Philippines still uses paper-based and film-based medical records particularly in recording medicine consumption and as the number of residents seeking consultations and medications from the local health units are increasing year by year, the study aims to determine the forecasting model to be used and the functionalities that could unify and integrate all local health units for efficient inventory and monitoring of illnesses and the medicines and supplies disbursed to its residents. Specifically, the study sought to answer the following 
questions: 1) What forecasting model could serve as a decision-support to aid the administrative planning determining the number of medicines needed as well as its distribution to the local health units based on its existing data and processes? 2) What are the system functionalities would pave way to more trailing capabilities, easy and fast tracking on to whom, down to the lowest-level the medicines where acquired and distributed?

\section{LITERATURE REVIEW}

\subsection{Electronic Health/ Patient Record}

Liang et al [7] defined that EHR supports the ever-increasing need for comprehensive information requirements among medical facilities [12] and that careful implementation of IT technologies ultimately benefits the both patients $[18,29]$ and the health institutions [5]. As discussed by Adler-Milstein et al. [31], EHR is one of the key contributors for improving services among hospitals. Hochgesang et al. [16] highlighted the challenges in implementing a nationwide monitoring system among public health facilities. Whereas, despite challenges in implementing an EHR, beta results yielded some positive results [5]. For example, due to the EHR, they acquired positive results in improving quality of care using a more accurate and shared patient record across health institutions [5]. Whereas, one study [6] detailed the need for improvements on EHR particularly in its integration of the system to other systems and databases. Filker et al [19] emphasizes the role of clinical management system in quality assurance while Shield et al [28] said that sharing of medical information through EHR improves workflow which also leads to improving health care systems [30]. Additionally, the oversight function of a clinical system is vital towards a more efficient quality of patient care and services [19]. Fritz et al [9] emphasizes that to efficiently use and maximize the amount of resources an organization have; it is vital for people to have the right information at the right time. Having a reliable data supports health institutions that lacks enough resources. [14] that technology has a potential in improving services and processes in health facilities such as increase documentation quality, administration efficiency, better coordination of care.

\subsection{Forecasting with SMA}

Time series model is a known approach that uses historical data to address the present challenges and tries to predict the future based on trends and pattern found within the dataset. [24]. Among them, the most well-known is the SMA due to its simplicity [32]. The SMA forecast uses a number of the most recent actual data values in generating a forecast. SMA eliminates randomness by taking a set of observed values, finding their average and then using that average as a forecast for the coming period. The actual number of observations included in the average is specified by the forecaster and remains constant. The term SMA is used because as each new observation becomes available, a new average can be computed and used as a forecast $[23,25-26]$, and it is suitable for long-term prediction [4]. The practice of forecasting has enormous opportunities along with the Supply Chain Management (SCM) strategy. Competitive situation always asks for change rapidly and this would be the continuous process for sustainable growth. Forecasting could be used in other than direct materials requirement such as spare parts, office stationery and other supplies which are untapped areas in the organization [3].

In this regard, SMA known and widely used by traders as a tool. Aside in market analysis, SMA became useful in forecasting needs in different industries, which include food, health and others. One study [2] was conducted to point out two fundamental problems in inventory management of the restaurant, (1) the use of qualitative method that dominate the planning process and (2) inconsistency of staff's performance. The study recommended the use of two operation management tools: (1) quantitative method to calculate the demand forecast using a SMA and (2) the calculation of optimal order quantity using a computerized Material Requirement Planning system, to solve the problems in planning process of the inventory management.

Another study is in the automobile industry, to which the SMA was used, it was proven to be useful in demand forecasting. Roslin et al [8] revealed that the data that forecasted by SMA technique gives the most accurate data and the technique was selected to be integrated in the development of IMS model. While a study [20] concluded that by applying SMA, it was expected to maintain efficient inventory by avoiding storing long term spare parts to be able to increase benefits and make good relation with customer in Bilaspur, India and that by applying SMA can results to an efficient inventory maintenance. Other studies have used SMA to forecast short-term fuel sales at retail outlets [15], solar power generation [22], garment industry [33], and the demand for boot in Shoe Industry [1].

\section{METHODOLOGY}

The study used qualitative technique such as observations among health unit's existing transactions and processes, the study also used face-to-face interviews with 12 informants in one city in Pampanga. These people were selected due to their background and knowledge on the existing conditions, processes, and services in their local health units.

The informants were interviewed in 10 different occasions due to the availability of their schedules. All informants have background in medicine while 10 out of 12 are health unit 
heads. Interviews conducted to the informants lasted less than hour. Each informant was interviewed on the spot and their responses were recorded using pen and paper. The responses were then analyzed, categorized, and summarized to determine how the system should forecast and what other software functionalities should be added to the system. For example, if one informant mentioned that there should be data-sharing of medicines among local health units then the system must have a capability in exchanging information to other local health units.

For the system development, the study will use agile development model due to its user-centered approached to system development. The agile model to be use in the study is composed of three phases (unit, integration, and acceptance testing). Through these phases, the researcher will be guided in concentrating in developing the system to work through rapid feedback in a continuous, regular, and sustainable development. An initial alpha testing was also conducted to test the compliance of the system towards ISO 25010.

\section{RESULTS AND DISCUSSION}

Based on interviews with the informants, the number of health units in a city depends on the number of barangay (or community). The one that was used in this study, have five (5) rural health units (RHU) which are further divided into 42 local health units (LHU). Rural health units can supervise up to 9 LHUs. Both RHUs and LHUs are headed by the city health office (CHO). For most part, the CHO's function is to monitor and distribute all the medicines to RHUs and LHUs. Although the LGU was the one who decides how many medicines will be procured for a fiscal year, the $\mathrm{CHO}$ provides inputs and recommendations based on the consolidated data from RHUs and LHUs. The CHO, RHUs and LHUs also receives medicines and other supplies from different organizations such as other local government units (LGUs), Non-government agencies (NGOs), and Department of Health (DOH). These data are sometimes not accounted to the overall medical supplies known by the CHO.

According to the informants, most of the illnesses and the medicines disbursed to patients are written to a logbook and then transferred to a spreadsheet file. Every month the health units' forwards summary of these information to the CHO. As a general rule, the number of medicines is projected every year is based on the number of residents in which the specific health unit is located.

For the initial phase, actual medicinal data is needed first for the forecasting technique, the researcher was able to acquire five-year span of medicinal records in the $\mathrm{CHO}$. This data was used to test the forecasting part of the system. In the conceptualization of the system and based from the information given by the informants, it was determined that a web-based system is the most appropriate platform due to the availability of internet to each health units and their distance to one another. Moreover, a log-in functionality is added to the system to provide additional layer of security due to the confidentiality of the data within the system. The informants mentioned that another security protocol is needed to prevent unauthorize people in accessing sensitive information as well as a compliance to the Data Privacy Act of 2012 of the Philippines, this functionality was supported by Kagalwalla et al [29] which mentioned that adequate security measures should be in place to protect the confidentiality of patient records which ultimately lead to gaining the trust of the patient to the system.

Next step in the development process is that the system needs to have a database of residents to effectively monitor all the disbursement of medicines as well as the illnesses. Since not all the residents go to the health units, the informants said that the system should have a capability to enroll a resident to the system only once, this functionality was agreed upon by most of the informants as it will help them to properly monitor the disbursement of medicines which promotes accountability as well as the browsing the medical record (Figure 5) of the resident across all health units (Figure 4). It was mentioned by the informants that the resident may only need to provide an identification card or a residence certificate from the barangay hall to register to the system. This resolves the issue of having them write the record of one resident several times as well as the capability to easily access, tracks, and monitor the medical data of a resident from another health unit.

After logging to the system, the health officer or the health unit head will be redirected to the main dashboard (Figure 1) of the system. There are three dashboards within the system (i.e., CHO, RHU, LHU).

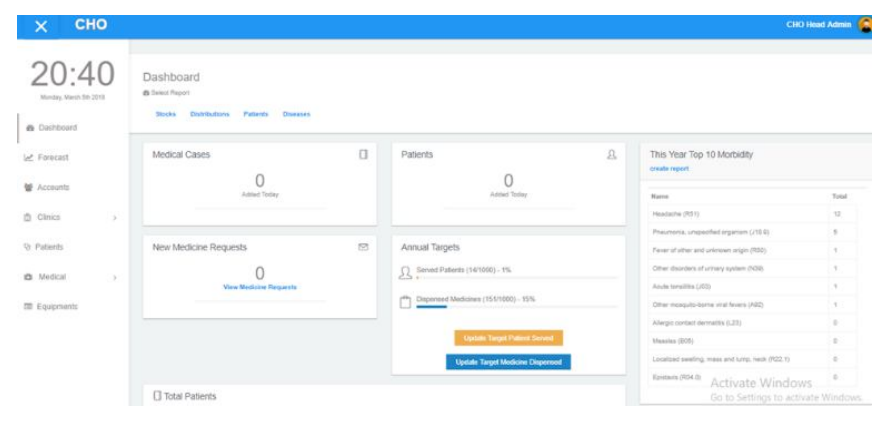

Figure 1: User Dashboard

The user will be prompted with summary of data across all health units (Figure 5), different visualization charts was added to the system to help users to understand more of its data. The informants said that charts are needed as this will help them to easily monitor and understand the data within the system (Figure 2) particularly the frequencies of medicines and illnesses recorded by health units. Since there are three (3) main users as determined by the informants, the system have a 3 layered user access (i.e., CHO Officer, RHU 
Head, LHU Head), the dashboard of CHO can view all the detailed information of RHUs and LHUs, the RHU on the other hand can only see the data coming from the assigned LHUs to them. Additional capability is that any RHU or LHU may add information on new medicines and/or supplies provided by other agencies or organization. Through this, the $\mathrm{CHO}$ will efficiently monitor all outgoing and incoming medicines and/or supplies within all health units along with the illnesses associated with them. With this the health units particularly the $\mathrm{CHO}$ and the $\mathrm{LGU}$ can easily monitor the rate or trend of diseases within the scope of each LHU and help them to visualize and determine if there is possible outbreak of a specific disease through its dashboard and reports produced by the system. Another functionality is that the $\mathrm{CHO}$ may add information of supplies, the medicines (i.e. Generic or Brand Name) as well as he illnesses information based on the international code of diseases (ICD) of World Health Organization (WHO), other health unit heads may also add the information upon the approval of the CHO.

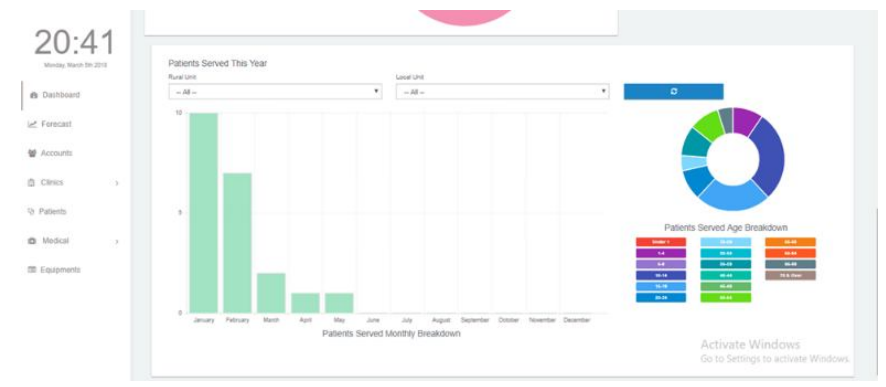

Figure 2: Data Visualization using Graphs

Another information acquired from the interviews with the informants, is that there should be a clear and easy way to forecast the number of medicines/ supplies needed in a fiscal year. For this case, the researcher used SMA as the forecasting technique to be use within the system. SMA is selected because its objectivity and it eliminates randomness by taking a set of observed values and finding their average and then use that average to forecast. Additionally, SMA is used because as new data becomes available, a new average can be computed and use as a forecast [23].

Suryapranata [4] on the other hand, highlighted the practical use of SMA for long-term trend prediction. Furthermore, SMA is known for its simplicity, stability, ease of use and less prone to extreme changes due to various changes [11]. Svetunkov et al [32] concluded that SMA is efficient as a forecasting model and it works best in point forecast and prediction interval with normal and cumulative values. Additionally, Yunishafira [33] proved that SMA can be used to reduce the overstock, understock as well as maximize profitability. Castillo et al [34] pointed out that SMA can be used for 6 to 12 months of historical data which is similar to the current situation in the CHO. Using the SMA as the model, the results can be printed by the user to use as a supporting document when the LGU ask for the number of needed medicines and supplies.

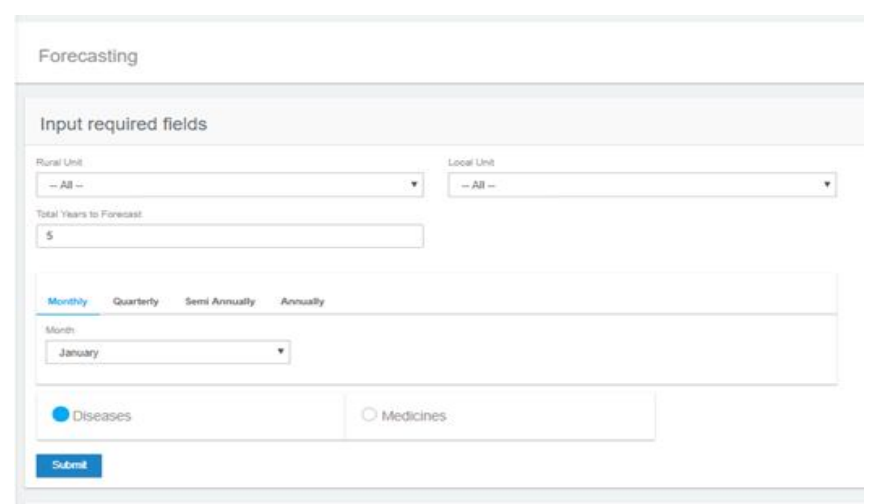

Figure 3: Forecasting Interface

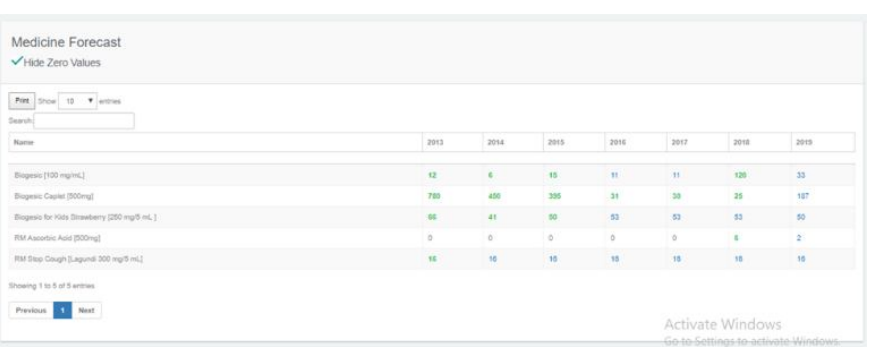

Figure 4: Sample Forecasted Results

In forecasting the projected number of medicines and supplies needed for the next fiscal year, the system will not use the number of residents as its data but instead it will use the number of medicines and supplies consumed by the community over the years (Figure 4). The system has also a functionality wherein the user may choose up to how many years of historical data will be used to forecast the required medicines and supplies. The user may also forecast as a whole or for a specific health unit (Figure 3). Four time series are used within the system (i.e., Monthly, Quarterly, Semi-Annual, Annually). The system also has capability to allocate how many medicines and supplies will be distributed to a specific health unit based on the forecasted results. In the allocation process, the system will not use the number of expired medicines as well as the best-before dates a parameter during forecasting since this are not considered as consumed.

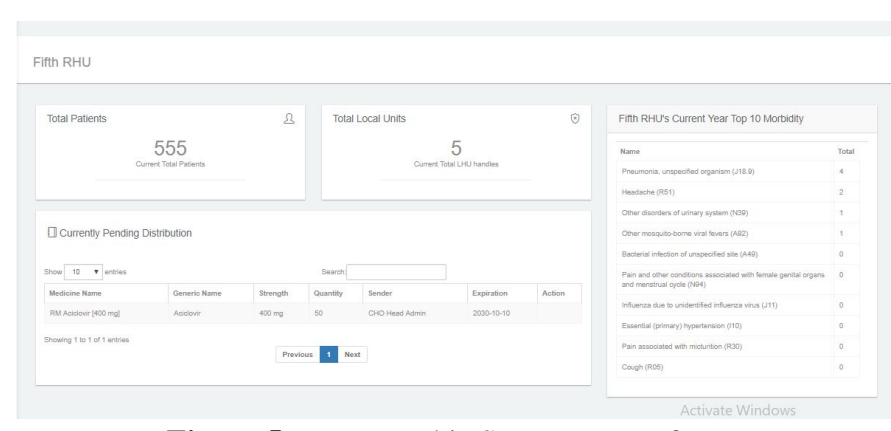

Figure 5: Demographic Summary Interface 


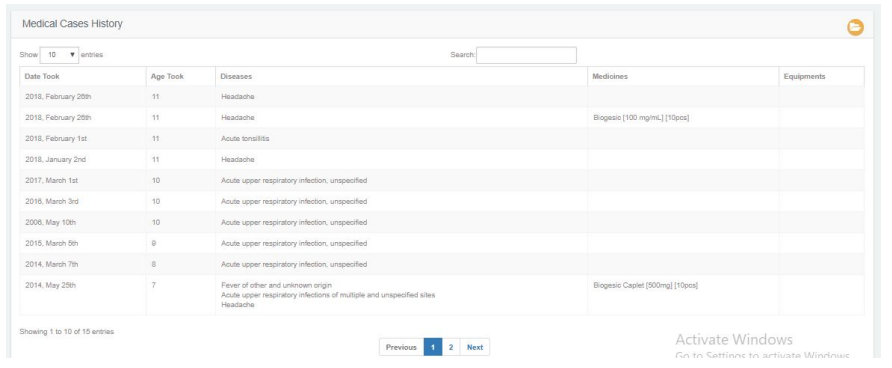

Figure 6: Resident Medical History

Another capability mentioned by the informants is that health units must be able to see within the system if a specific medicine and supply is available other health units. This functionality is warranted by the informants as this will lessen the unused medicines and maximized the supply within the city.

Table 1: Summary of Alpha Test Results

\begin{tabular}{|c|c|c|}
\hline Quality Standard & Mean & Interpretation \\
\hline $\begin{array}{c}\text { Functional } \\
\text { Suitability }\end{array}$ & 3.80 & Very Great Extent \\
\hline $\begin{array}{c}\text { Performance } \\
\text { Efficiency }\end{array}$ & 3.67 & Very Great Extent \\
\hline Compatibility & 3.70 & Very Great Extent \\
\hline Usability & 3.60 & Very Great Extent \\
\hline Reliability & 3.65 & Very Great Extent \\
\hline Security & 3.80 & Very Great Extent \\
\hline Maintainability & 3.72 & Very Great Extent \\
\hline Portability & 3.87 & Very Great Extent \\
\hline Overall Mean & 3.73 & Very Great Extent \\
\hline
\end{tabular}

Table 1 shows the evaluation of 5 ICT experts from both academe and industry practitioners towards the system using the 8 criteria of ISO 25010 in which the mean is 3.73 , the results indicated that the system is acceptable in great extent and has satisfied the quality standard requirements in building a system.

\section{CONCLUSION AND FUTURE WORK}

The paper describes how an interoperable health system can support the decision-making process of the health units. It is found that SMA is the simplest forecasting technique which can be used by health units. It was also found that the user may alternatively use historical data on medicine and supplies consumption as parameter for projecting the required medicines in four time series. The study also presented ways on how to improve the traceability of the medicines and supplies distributed to the residents thus enhancing oversight function of the $\mathrm{CHO}$ and accountability of health units.

After the completion of the system, it is recommended that the system could be as well implemented in other communities. A study on the actual use and effectivity of the system can be initiated. A beta and user acceptability testing can also be started to determine if it suited the needs of the community is recommended. Future researchers may consider the applicability of mobile application as well as to develop and integrate the services offered by local health units to the mobile application to enhance delivery of medical care and proactive monitoring of residents. The use of other forecasting algorithm with varying historical data together with other applicable allocation algorithm in which the expiration and best-before date of the medicines can be added as parameters are worth pursuing to further enhance the capability of the system. Likewise, new emerging technologies and approaches (i.e., data mining) may be explored in future studies.

\section{ACKNOWLEDGEMENT}

The author is indebted to the Don Honorio Ventura State University for the funding and to the informants who provided the relevant information for the completion of this study.

\section{REFERENCES}

1. A. P. Singh, M. K. Gaur, D. KumarKasdekar, and S. Agrawal. A Study of Time Series Model for Forecasting of Boot in Shoe Industry, International Journal of Hybrid Information Technology, vol. 8, no.8, pp. 142-152, Jan. 2015. https://doi.org/10.14257/ijhit.2015.8.8.13

2. A. Putra and G. Yudoko. An Analysis of Inventory Management at MJS Restaurant, Jakarta, Journal of Business and Management, vol. 2, no. 2, pp. 190-205, 2013.

3. A. R. Albarune and M. M. Habib. A Study of Forecasting Practices in Supply, International Journal of Supply Chain Management, vol. 4, no. 2, pp. 55-61, June 2015.

4. A. Suryapranata. Forecasting Framework for Inventory and Sales of Short Life Span Products, M.S. thesis, Delft University of Technology, Delft, Netherlands, 2003.

5. A. Takian, N. and Barber. We are bitter, but we are better off: case study of the implementation of an electronic health record system into a mental health hospital in England, BMC Health Services Research, vol. 12, no. 1, Dec. 2012.

https://doi.org/10.1186/1472-6963-12-484

6. C. Bossen, L. G. Jensen, and F. W. Udsen. Evaluation of a comprehensive EHR based on the DeLone and McLean model for IS success: Approach, results, and success factors, International Journal of Medical Informatics, vol. 82, no. 10, pp. 940-953, Oct. 2013.

7. C. Liang, D. Gu, F. Tao, H. Jain, Y. Zhao, and B. Ding. Influence of mechanism of patient-accessible hospital information system implementation on doctor-patient relationships: A service fairness 
John Paul P. Miranda, International Journal of Advanced Trends in Computer Science and Engineering, 9(1.3), 2020, 182- 188

perspective, Information and Management, vol. 54, no. 2, pp. 57-72, Jan. 2017.

8. E. N. Roslin, S. N. Razak, M. Z. Bahrom, and M. A. A. Rahman. Conceptual Model of Inventory Management System using an EOQ Technique - A Case Study in Automotive Service Industry, Journal of Science \& Engineering Technology, vol. 2 no. 2, Sept. 2016.

9. F. Fritz, B. Tilahun, and M. Dugas. Success criteria for electronic medical record implementations in low-resource settings: a systematic review, Journal of the American Medical Informatics Association, vol. 22, no. 2, pp. 479-488, March 2015.

https://doi.org/10.1093/jamia/ocu038

10. H. K. Takhti, A. A. Rahman, S. Abedini, and S. Abedini. Impact of Hospital Information Systems on patient care: Nurses' perceptions, Canadian Journal of Nursing Informatics, vol. 6, no. 4, April 2012.

11. J. B. Maverick. What are the main advantages and disadvantages of using a Simple Moving Average (SMA)? Investopedia, April 2020.

12. J. Spetz and D. Keane. Information Technology Implementation in a Rural Hospital: A Cautionary Tale, Journal of Healthcare Management, vol. 54, no. 5, pp. 337-347, Oct. 2009.

13. K. Ratchinsky. Top 5 health IT trends for 2015: What's top of mind?, Healthcare IT News, Jan. 2015.

14. L. Nguyen, E. Bellucci, and L. T. Nguyen. Electronic health records implementation: An evaluation of information system impact and contingency factors, International Journal of Medical Informatics, vol. 83, no. 11 pp. 779-796, Nov. 2014.

15. M. Danuri and K. I. Satoto. Design System Fuel Inventory Control in Gas Stations with The Concept of Min-Max Stock Level and Time Phased Order Point Case Study Gas Stations, in Proc. of The 1st International Conference on Information Systems For Business Competitiveness (ICISBC) 2011, Central Java, Indonesia, Dec. 2011, pp. 317-324.

16. M. Hochgesang, S. Zamudio-Haas, L. Moran, L. Nhampossa, P. Laura, H. Leslie, and S. Shade. Scaling-up health information systems to improve HIV treatment: An assessment of initial patient monitoring systems in Mozambique, International Journal of Medical Informatics, vol. 97, no. 1, pp. 322-330, Jan. 2017.

https://doi.org/10.1016/j.ijmedinf.2016.11.002

17. M. Tapas. Importance of Digitizing Paper Documents, SARANGSoft, Aug. 2015.

18. M. Walji, D. Taylor, J. Langabeer, and J. Valenza. Factors Influencing Implementation and Outcomes of a Dental Electronic Patient Record System, Journal of Dental Education, vol. 73, no. 5, pp. 589-600, May 2009.

19. P. Filker, E. Muckey, S. Kelner, J., and Kodish-Stav. Taking a Quality Assurance Program from Paper to Electronic Health Records: One Dental School's
Experience, Journal of Dental Education, vol. 73, no. 9, pp. 1095-1101, Sept. 2009.

20. S. Nayak, M. Gupta, and A. Kachhwaha. Forecasting of Spare Parts Inventory by Exponential Method, Journal of Harmonized Research in Engineering, vol. 3, no. 1, pp. 1-4, Jan. 2015.

21. T. Wang and D. Dolezel. Usability of Web-based Personal Health Records: An Analysis of Consumers' Perspectives, Perspectives in Health Information Management, vol. 13, no. 1, pp. 1-14, April 2016.

22. V. P. Singh, V. Vijay, B. Ravindra, and M. S. Bhatt. Impact of Trend and Seasonality in Forecasting of 5 MW PV Plant Generation using Simple Moving Average Method, International Journal of Computer Applications, vol. 130, no.1, pp. 5-9, Nov. 2015. https://doi.org/10.5120/ijca2015906840

23. W. Stevenson. Operations Management, 12th ed. New York, NY: McGraw-Hill Education, 2014, pp. 84-91.

24. D. Frechtling. Forecasting Tourism Demand: Methods and Strategies, Oxford, UK: Butterworth-Heinemann, 2001, pp. 20-27.

25. K. Molugaram and G. S. Rao. Statistical Techniques for Transportation Engineering, Oxford, UK: Butterworth-Heinemann, 2017, pp. 463-489.

26. K. Storm. Industrial Process Plant Construction Estimating and Man-Hour Analysis, 1st ed. Oxford, UK: Gulf Professional Publishing, 2019, pp. 1-21.

27. D. Kartawiguna, H. Prabowo, and T. Jap. The Role of Information Technology in Mediating the Effect of Medical Resources on Hospital Clinical Performance. International Journal of Advanced Trends in Computer Science and Engineering, vol. 8, no. 6, pp. 2887-2892, Nov. 2019.

https://doi.org/10.30534/ijatcse/2019/33862019

28. R. Shield, R. Goldman, D. Anthony, N. Wang, R. Doyle, and J. Borkan. Gradual Electronic Health Record Implementation: New Insights on Physician and Patient Adaptation, Annals of Family Medicine, vol. 8, no. 4, pp. 316-326, Aug. 2010.

29. N. Kagalwalla, T. Garg, P. Churi, and A. Pawar. A Survey on implementing privacy in Healthcare: An Indian Perspective, International Journal of Advanced Trends in Computer Science and Engineering, vol. 8, no. 3 pp. 963-982, June. 2019 https://doi.org/10.30534/ijatcse/2019/97832019

30. M. Vucha and A. L. Siridhara. High Speed Cryptography Architecture for Health Information Exchange, International Journal of Advanced Trends in Computer Science and Engineering, vol. 8, no. 4, pp. 1443-1448, Aug. 2019. https://doi.org/10.30534/ijatcse/2019/63842019

31. J. Adler-Milstein, A. J. Holmgren, P. Kralovec, C. Worzala, T. Searcy, and V. Patel. Electronic health record adoption in US hospitals: the emergence of a digital "advanced use" divide, Journal of the American Medical Informatics Association, vol. 24, no. 6, pp. 1142-1148, Nov. 2017. 
John Paul P. Miranda, International Journal of Advanced Trends in Computer Science and Engineering, 9(1.3), 2020, 182- 188

32. I. Svetunkova and F. Petropoulos. Old dog, new tricks: a modelling view of simple moving averages, International Journal of Production Research, vol. 56, no. 2, pp. 1-14, Sept. 2017.

33. A. Yunishafira. Determining the Appropriate Demand Forecasting Using Time Series Method: Study Case at Garment Industry in Indonesia, in International Conference on Economics, Business and Economic Education 2018, Central Java, Indonesia, pp. 553-564, Oct. 2018. https://doi.org/10.18502/kss.v3i10.3156

34. M. D. R. Castillo, M. M. Palavicini, R. Soto, and M. J. Cruz-Gomez. Double Weighted Moving Average: Alternative Technique for Chemicals Supplier's Sales Forecast, International Journal of Business Administration, vol. 7, no. 4, pp.58-66, July 2016. https://doi.org/10.5430/ijba.v7n4p58

35. National Archives of the Philippines Act of 2007

36. Privacy Guidelines For The Implementation Of The Philippine Health Information Exchange 